\title{
Estrogen treatment in vivo increases keratinocyte growth factor expression in the mammary gland
}

\author{
V K Pedchenko and W Imagawa
}

Department of Molecular and Integrative Physiology and Kansas Cancer Institute, University of Kansas Medical Center, Kansas City, Kansas 66160-7810, USA (Requests for offprints should be addressed to W Imagawa)

\begin{abstract}
Proliferation and differentiation of mammary epithelia are regulated by the combined action of systemic hormones and locally derived paracrine growth factors. Keratinocyte growth factor (KGF) is a potential candidate stromal factor that may participate in the hormonal control of stromal/ epithelial interactions. In this study, we have examined the in vivo effect of $17 \beta$-estradiol (E) treatment on KGF expression in mammary glands of peripubertal (5-weekold) and mature (11-week-old) mice. Mice received subcutaneous injections of hormone after which KGF mRNA levels were assayed by ribonuclease protection analysis of mammary gland RNA. E treatment caused a dose- and time-dependent increase in KGF mRNA levels in intact mice from both age groups. Neither $17 \alpha$-estradiol
\end{abstract}

nor progesterone injection affected KGF mRNA levels. Comparison of the relative expression of KGF in parenchyma-free fat pads and in intact glands demonstrated that the basal and E-dependent KGF mRNA levels did not require the presence of mammary epithelium. ELISA assay of KGF tissue content demonstrated that concomitantly with an up-regulation of mRNA, E treatment also increased KGF protein in mammary glands from peripubertal and mature mice. These data show that $\mathrm{E}$ treatment stimulates both KGF mRNA and protein expression in mammary stroma in vivo and raises the possibility that KGF has a role in E-regulated mammary gland development.

Journal of Endocrinology (2000) 165, 39-49

\section{Introduction}

Postnatal development of the mammary gland is regulated by coordinated interactions of estrogen (E) with other ovarian and pituitary hormones and locally produced growth factors (Topper \& Freeman 1980, Imagawa et al. 1994a). Accumulating evidence indicates that the stimulatory effect of $\mathrm{E}$ on mammary epithelial growth and morphogenesis requires the presence of stroma. Both mammary ductal epithelium and stroma possess estrogen receptors (Haslam \& Shyamala 1981) and are E targets. However, cultures of purified ductal epithelium that retain E receptors (Edery et al. 1985) lose their mitogenic response to E (Imagawa et al. 1985, Xie \& Haslam 1997). If mammary epithelium is cultured in association with stromal cells, the stimulation of DNA synthesis by E in mammary epithelium can be restored (Haslam 1986). Furthermore, in vivo studies show that cells proliferating in response to $\mathrm{E}$ (cap cells in end buds or luminal epithelium of mammary ducts) are estrogen receptor (ER)-negative (Daniel et al. 1987, Zeps et al. 1998) suggesting that E can indirectly stimulate ductal elongation and branching. Recent studies with tissue recombinants from ER knockout mice provide direct evidence that $\mathrm{E}$ regulation of epithelial proliferation in mammary gland is a paracrine event mediated by ER-positive stromal cells (Cunha et al. 1997, Cooke et al. 1998). However, little is known currently about the nature of the stromally derived paracrine growth regulatory molecules. It has been suggested that epidermal growth factor (EGF) and/or other members of the EGF family may modulate the effect of $\mathrm{E}$ on mammary epithelium (Ankrapp et al. 1998, Woodward et al. 1998).

Another attractive candidate for conveying such paracrine signals is a keratinocyte growth factor (KGF or FGF-7), which belongs to the fibroblast growth factor (FGF) family (Basilico \& Moscatelli 1992). KGF has a very distinct expression pattern; it is expressed in the stromal tissue of many organs, while its receptor (KGFR) is found only in the epithelium (Aaronson et al. 1991). This tissue-specific expression pattern suggests that KGF is a potential mediator of mesenchymal-epithelial interactions (Finch et al. 1995a, Rubin et al. 1995). A strong mitogenic effect of KGF has been demonstrated for a broad range of epithelial cells, including rodent mammary epithelium both in vitro (Imagawa et al. 1994b, Pedchenko \& Imagawa 1998) and in vivo (Ulich et al. 1994, Yi et al. 1994).

Examination of the hormonal regulation of KGF expression has shown that in primate endometrium KGF expression is activated by progesterone (Koji et al. 1994, Matsui 
et al. 1997), whereas in cultured human endometrial cells KGF expression could be significantly increased after long-term culture with the non-steroidal estrogen, diethylstilbestrol ( $\mathrm{Li} \&$ Rinehart 1998). Hormonal regulation of KGF expression has been studied in ovarian follicles where estrogen and human chorionic gonadotropin were found to stimulate KGF expression in cultured bovine theca cells (Parrott \& Skinner 1998). In the prostate, KGF is postulated to be an andromedin (Sugimura et al. 1996, Planz et al. 1998), although careful correlation of KGF expression with changes in gland cellularity in response to androgen suggests that androgen does not specifically activate KGF expression in vivo (Thomson et al. 1997, Nemeth et al. 1998).

Northern blot analysis of KGF expression during mouse mammary gland development showed differential expression of KGF (Coleman-Krnacik \& Rosen 1994). KGF expression was high in mammary glands from virgin and lactating mice, low in glands from pregnant mice, and apparently undetectable in parenchyma-free fat pads. An additional low molecular weight transcript appeared during pregnancy and was predominantly expressed in the lactating gland. These observations suggested that KGF synthesis could be under the control of mammogenic hormones, although this remained speculative. Since progesterone receptors are absent from the stroma, E and/or prolactin (PRL) are candidate mammogenic hormones that may possibly affect KGF expression. This effect for $\mathrm{E}$ could be direct since two half-palindromic E response elements have been identified in the promoter region of the human KGF gene (Finch et al. 1995b).

In the present studies we test the hypothesis that $\mathrm{E}$ may indirectly affect the growth of mammary epithelium cells by elevating KGF production in the stroma. Since it was shown that the response to ovarian steroids and their interactions with EGF are influenced by the developmental state of the mammary gland (Haslam et al. 1993, Ankrapp et al. 1998), we have examined the effect of $E$ on the level of KGF mRNA and protein in mammary glands of peripubertal (5-week-old) and mature, adult (11-weekold) mice. Mammary glands in intact peripubertal animals exhibit postpubertal ductal growth which is stimulated by sufficient $\mathrm{E}$ administration, while those from mature animals are developmentally dormant and undergo lobuloalveolar development when stimulated by E. We asked if there was a correlation between the effect of $E$ on mammary gland development and the pattern of KGF expression.

\section{Materials and Methods}

\section{Chemicals}

17 $\beta$-Estradiol (E), $17 \alpha$-estradiol and progesterone were purchased from Sigma Chemical Co. (St Louis, MO,
USA). Hormones were first dissolved in ethanol and then mixed with nine volumes of sesame oil.

\section{Animals}

Intact virgin $\mathrm{BALB} / \mathrm{CAnNCr}$ mice (Charles River, Wilmington, MA, USA) were used at 4 or 10 weeks of age. Mice were maintained under controlled temperature and lighting conditions, and were given food and water ad libitum. In all experiments three animals per treatment group were used. In separate experiments, parenchymafree or cleared inguinal mammary glands were obtained by excision, at 3 weeks of age, of the proximal portion of the fat pad containing the incipient mammary parenchyma (DeOme et al. 1959). Mice received daily subcutaneous injections of $\mathrm{E}(0 \cdot 2-200 \mu \mathrm{g})$ or progesterone $(400 \mu \mathrm{g})$ in $50 \mu \mathrm{l} 10 \%$ ethanol/sesame oil for 1 to 7 days; control animals received vehicle only. At termination, intact or cleared fourth inguinal mammary glands (with lymph nodes removed) were collected for RNA or protein extraction. Thoracic mammary glands were prepared for whole mount analysis of gland morphology by fixation in methacorn followed by defatting in acetone, and staining with iron-hematoxylin. To assess the effectiveness of $\mathrm{E}$ delivery, uteri were excised and weighed for all experiments.

All animals were maintained in accordance with the NIH Guide for Care and Use of Laboratory Animals, and all procedures described here were approved by the Kansas University Medical Center Animal Care and Use committee.

\section{Ribonuclease protection assay}

The probe used for RNase protection assays was a $227 \mathrm{bp}$ PstI/SmaI fragment of mouse KGF cDNA cloned into pGEM3Zf(-) vector (Promega, Madison, WI, USA) (Finch et al. 1995a). After linearization with HindIII, anti-sense probe was synthesized with T7 RNA polymerase and $60 \mu \mathrm{Ci}\left[\alpha_{-}{ }^{32} \mathrm{P}\right] \mathrm{UTP}(800 \mathrm{Ci} / \mathrm{mmol}$; DuPont New England Nuclear, Wilmington, DE, USA). Fulllength transcript with specific activity $\sim 2 \times 10^{8}$ c.p.m. $/ \mu \mathrm{g}$ was recovered after electrophoresis on $5 \%$ polyacrylamide, $7 \mathrm{M}$ urea-Tris/borate/EDTA gel. A $\beta$-actin probe with a protected fragment size of 125 nucleotides (Ambion, Austin, TX, USA) was used as an internal control for gel loading and RNA integrity. It was labeled to lower specific activity using $100 \mu \mathrm{M}$ UTP and $5 \mu \mathrm{Ci}\left[\alpha-{ }^{32} \mathrm{P}\right] \mathrm{UTP}$ in order to produce signals of a comparable intensity to KGF in the RNase protection assay.

Total RNA was isolated from the fourth pair of inguinal mammary glands after homogenization in TRIzol reagent (Life Technologies, Grand Island, NY, USA). The RNase protection assay was performed with $20 \mu \mathrm{g}$ total RNA, 80000 c.p.m. labeled KGF probe and 20000 c.p.m. 
$\beta$-actin probe using an RPA II Kit (Ambion). After hybridization overnight at $45{ }^{\circ} \mathrm{C}$ and RNase digestion, protected fragments were resolved on $5 \%$ polyacrylamide$7 \mathrm{M}$ urea-Tris/borate/EDTA gels which were subsequently exposed to autoradiography film at $-70{ }^{\circ} \mathrm{C}$ with an intensifying screen. Band intensities, in the linear range of the film response, were quantified on a Molecular Dynamics Personal Densitometer SI using ImageQuant 4.2 software (Molecular Dynamics, Sunnyvale, CA, USA). Appropriate negative control samples contained yeast tRNA instead of mouse RNA to verify completeness of RNase digestion. Positive controls were not treated with RNase and confirmed that both probes were used in about 100-fold excess with respect to the concentration of target mRNA. All data for KGF mRNA expression were normalized to corresponding $\beta$-actin bands and usually expressed as a percentage of controls, as indicated in the figure legends.

\section{ELISA for KGF}

Combined fourth inguinal mammary glands were homogenized by Polytron in $1.5 \mathrm{ml}$ of a cold buffer containing $1 \mathrm{M} \mathrm{NaCl}, 20 \mathrm{mM}$ Tris-HCl (pH 7.4), 5 mM EDTA, $1 \mathrm{mM}$ PMSF, $10 \mu \mathrm{g} / \mathrm{ml}$ aprotinin, $10 \mu \mathrm{g} / \mathrm{ml}$ leupeptin, and $10 \mu \mathrm{g} / \mathrm{ml}$ pepstatin. After centrifugation at $13000 \times \boldsymbol{g}$ for $20 \mathrm{~min}$ at $4{ }^{\circ} \mathrm{C}$, supernatants were collected and the total protein concentration was measured using the BCA reagent (Pierce, Rockford, IL, USA).

Immulon-2 polystyrene microtiter plates (Dynatech, Chantilly, VA, USA) were coated overnight at $4{ }^{\circ} \mathrm{C}$ with $50 \mu \mathrm{l} /$ well of a goat polyclonal antibody to KGF $(10 \mu \mathrm{g} / \mathrm{ml}$ in PBS; R\&D Systems, Minneapolis, MN, USA). After blocking with $3 \%$ BSA in PBS, serial dilutions of a $1 \mathrm{ng} / \mathrm{ml}$ stock of a recombinant human KGF (Promega) in homogenization buffer or mammary gland extracts were incubated at $100 \mu \mathrm{l} /$ well overnight at $4{ }^{\circ} \mathrm{C}$. Highly homologous human recombinant KGF was used as a standard since mouse protein is not available commercially. After 5 washes with $200 \mu \mathrm{l} 0 \cdot 05 \%$ Tween-20 in PBS, $50 \mu \mathrm{l}$ rabbit polyclonal antibody to recombinant KGF $(5 \mu \mathrm{g} / \mathrm{ml}$; Chemicon International, Temecula, CA, USA) were added to each well and the plate was incubated for $4 \mathrm{~h}$ at room temperature. After washing as above, horseradish peroxidase-conjugated goat anti-rabbit immunoglobulin $\mathrm{G}$ (Calbiochem, Cambridge, MA, USA) diluted 1:500 with $1 \%$ BSA in PBS was added to the wells for $4 \mathrm{~h}$ and washed as above. Then $100 \mu \mathrm{l} 0.1 \mathrm{mg} / \mathrm{ml}$ tetra-aminobenzidine, $1.3 \mathrm{mM}$ hydrogen peroxide in $0.1 \mathrm{M}$ sodium acetate buffer ( $\mathrm{pH}$ 6.0) were added to each well. Color development was stopped after $30 \mathrm{~min}$ by the addition of $50 \mu \mathrm{l}$ $1 \mathrm{M}$ sulphuric acid to each well and optical density was measured at $450 \mathrm{~nm}$ with reference at $570 \mathrm{~nm}$ using a MRX Microplate reader (Dynatech). The KGF concentration in samples was determined using hyperbolic fitting of the standard curve (Studnicka 1987). In the range of 16 to $1000 \mathrm{pg} \mathrm{KGF/ml,} \mathrm{the} \mathrm{average} \mathrm{intra-assay} \mathrm{coefficient}$ of variation was $4 \cdot 0 \%$, and the interassay coefficient of variation calculated from 6 experiments was $11 \cdot 7 \%$. KGF recovery, estimated by addition of known amounts of human KGF to mammary gland extracts, was 95\%.

\section{Statistical analysis}

All data presented are means \pm S.D. combined from at least 6-9 observations from 2-3 independent experiments. Single comparisons were performed using Student's twotailed $t$-test; for multiple comparison between various treatment groups, data were analyzed by one-way ANOVA followed by the Student-Newman-Keuls test. All differences were considered significant at $P<0 \cdot 05$.

\section{Results}

Effect of $E$ on KGF $m R N A$ expression in mammary glands of 5-week-old mice

RNase protection assay was used to examine E-dependent changes in KGF gene expression in mammary glands of peripubertal BALB/c mice. As illustrated in Fig. 1A, daily subcutaneous injections of $17 \beta$-estradiol (E) for 7 days produced a dose-dependent increase in KGF mRNA level. To monitor the effectiveness of $\mathrm{E}$ injections, uterine wet weight was also monitored (Fig. 1B). The uterus is more sensitive than the mammary gland to $\mathrm{E}$. The lowest dose of $\mathrm{E}$ that caused a significant increase in the steadystate level of KGF mRNA was $2 \mu \mathrm{g}$. The maximal effect of E (2.5-fold) was observed at $20 \mu \mathrm{g}$ per injection, without any further increase at the higher dose. Therefore, this dose was used to investigate the time course of the $\mathrm{E}$ response. A small increase in KGF mRNA levels was first detected 1 day after injection of a single dose of $E$ (Fig. 2). This stimulation gradually increased in magnitude over 7 days. As expected, the basal level of KGF expression in control mice was not changed during the experiment.

\section{Effect of $E$ on KGF $m R N A$ level in mammary glands of 11-week-old mice}

In mature 11-week-old mice, treatment with $\mathrm{E}$ also caused a dose-dependent increase in KGF mRNA levels (Fig. 3). The maximal increase in KGF mRNA (1.6-fold) was observed at an injected dose of $200 \mu \mathrm{g}$ E. Time course studies showed an increase in KGF mRNA levels after 1 and 7 days of $E$ treatment, with a greater difference between control and E-treated animals observed at 7 days (Fig. 4). Surprisingly, on day 3 no effect of $E$ was observed although there was an increase in uterine wet weight. There was no difference detected in the basal level of KGF mRNA in pubertal compared with mature mice $(0 \cdot 27 \pm 0 \cdot 02$ and $0 \cdot 27 \pm 0.03$ arbitrary units respectively, $n=9)$. However, the percentage E-induced increase in 

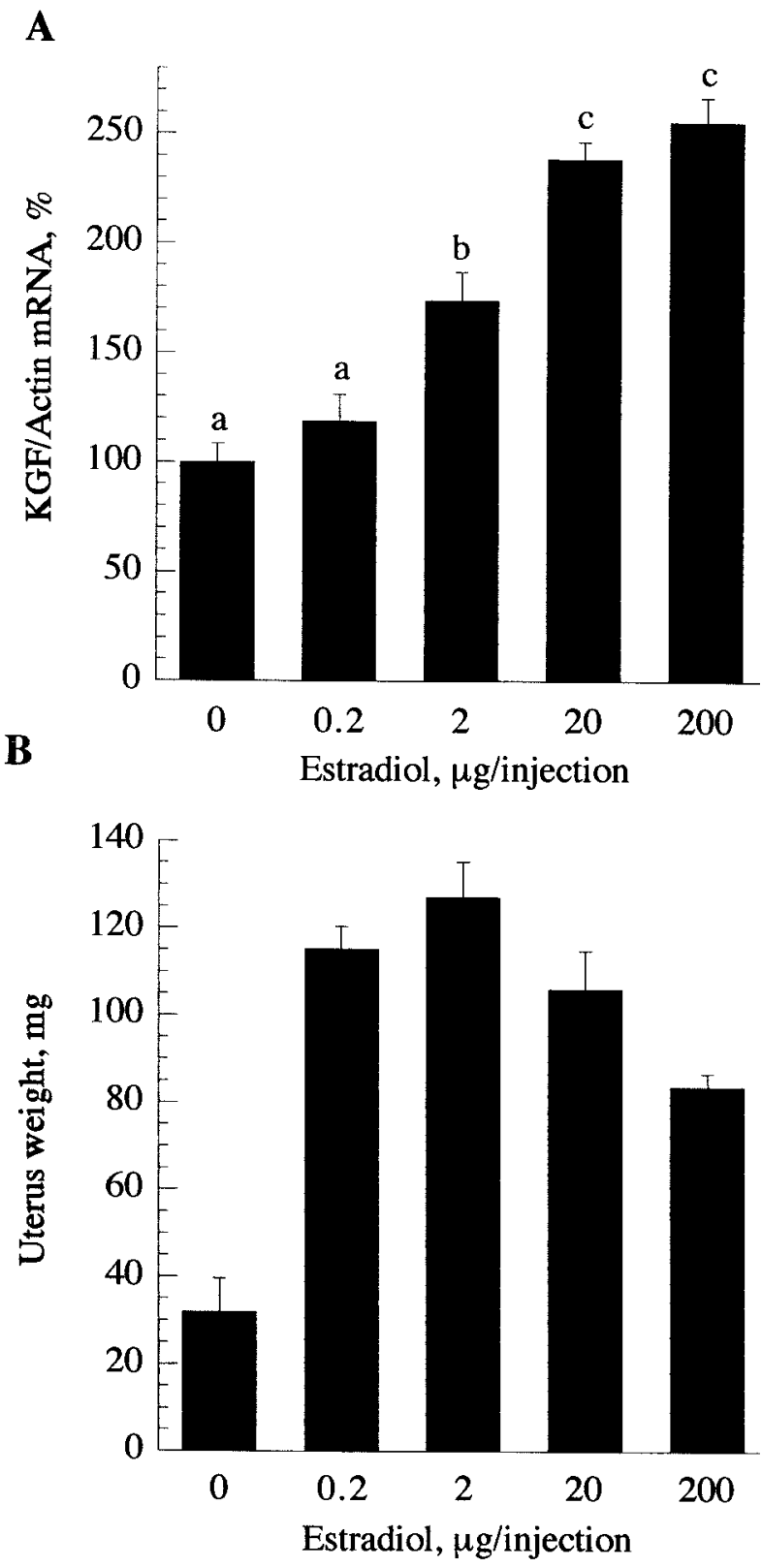

Figure 1 Effect of $17 \beta$-estradiol (E) on expression of KGF mRNA in mammary glands of 5-week-old BALB/C mice. (A) Starting from 4 weeks of age, mice were injected daily for 7 days with increasing doses of $E$, and KGF mRNA expression in mammary glands was analyzed by RNase protection assay as described in Materials and Methods. The data were corrected for actin and expressed as the percentage change compared with the value for vehicle-treated animals, which was arbitrarily set at $100 \%$. Bars represent means \pm S.D. from three experiments $(n=9)$. Significant differences between groups $(P<0 \cdot 01$, by Student-Newman-Keuls test) are indicated by different letters (a, b, c) above each bar. (B) Effect of $\mathrm{E}$ on uterine wet weight. Data represent means \pm S.D. from three experiments.

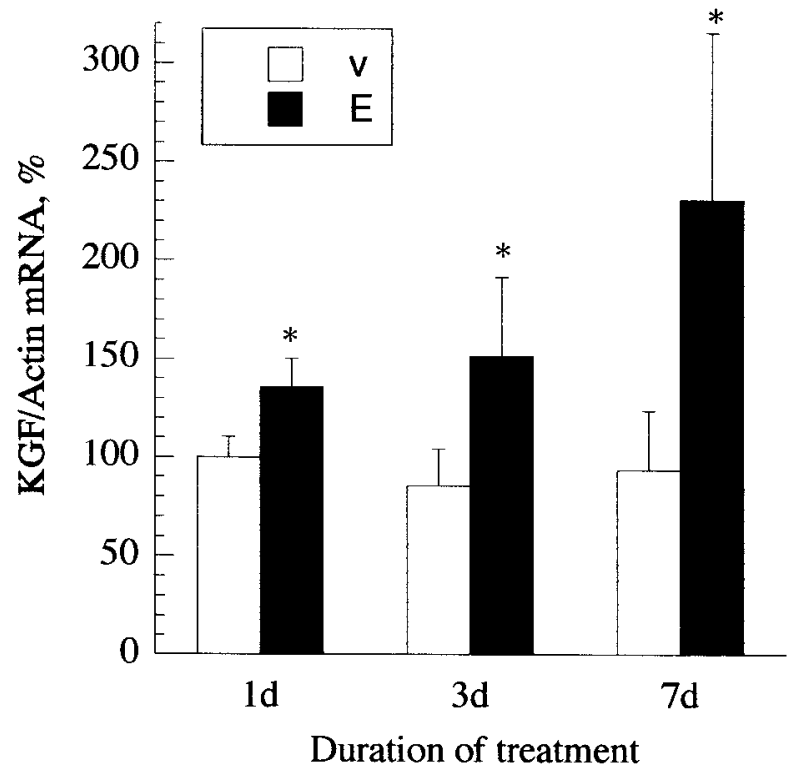

Figure 2 Time course effect of $17 \beta$-estradiol (E) on KGF mRNA levels in mammary glands of 5-week-old BALB/c mice. Mice were injected daily with vehicle control (v) or $20 \mu \mathrm{g}$ E. After the indicated time ( $d$, day), total RNA was extracted from mammary glands and KGF mRNA levels were determined as described in Fig. 1. The data are expressed as percentage change of vehicletreated animals at day 1 . Bars represent means \pm S.D. $(n=6)$ from two experiments. ${ }^{*} P<0.05$ vs respective vehicle control group (unpaired Student's $t$-test).

KGF mRNA was higher in 5-week-old (241 $\pm 5 \%, n=5)$ compared with 11 -week-old $(149 \pm 14 \%, n=7)$ animals $(P<0 \cdot 01)$.

\section{Estrogen specificity}

To address the question of specificity of the $\mathrm{E}$ effect on KGF expression, 5-week-old mice were injected with the non-receptor binding isomer of E, 17 $\alpha$-estradiol, at $20 \mu \mathrm{g}$ per injection for 7 days. This treatment resulted in an increase in uterine weight which was about $20 \%$ less than that produced by a corresponding dose of $17 \beta$-estradiol, but it had no effect on the level of KGF mRNA in the mammary gland (Fig. 5). This strict specificity of the E effect suggests that it is ER mediated.

Progesterone, administered similarly to E above, also did not affect KGF expression at a dose of $400 \mu \mathrm{g} /$ injection (Fig. 5), which is sufficient to stimulate ductal growth (VK Pedchenko \& W Imagawa, unpublished observations). This indicates that the mechanism for the E-induced increase of KGF steady-state level is not mediated by an increase in the circulating level of progesterone.

\section{Effect of E on mammary gland morphology in pubertal and} adult mice

In order to determine if the $\mathrm{E}$ effect on KGF gene expression could be associated with an effect on mammary 


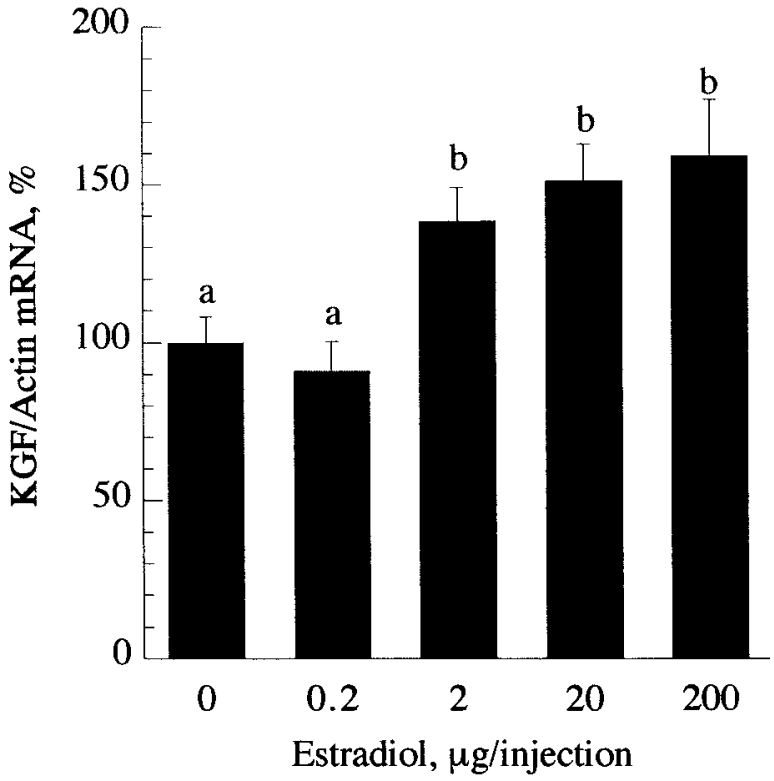

Figure 3 Effect of $17 \beta$-estradiol (E) on KGF mRNA levels in mammary glands of 11-week-old BALB/c mice. Starting from 10 weeks of age mice were injected daily for 7 days with increasing doses of $E$, and KGF mRNA expression was analyzed as described in Fig. 1. Values are expressed as percentage of vehicle-treated animals. Bars represent means \pm S.D. $(n=9)$ from three experiments. Significant differences between groups $(P<0 \cdot 05$, by Student-Newman-Keuls test) are indicated by different letters.

gland morphology, we analyzed whole mounts collected from E-treated 5- and 11-week-old mice. In control 5 -week-old mice, epithelial components fill about $30 \%$ of the mammary fat pad with clearly distinguished terminal end buds (Fig. 6a). E treatment for 7 days increased the number of end buds and caused atypical non-dichotomous lateral branching and premature lobular-like development (effect of $20 \mu \mathrm{g}$ dose shown in Fig. 6b, e). This effect was dose-dependent. The lowest dose of $\mathrm{E}$ had no effect on morphology, the effect was subtle at the $2 \mu \mathrm{g}$ dose, and pronounced at the $20 \mu \mathrm{g}$ and $200 \mu \mathrm{g}$ doses.

In control adult mice (Fig. 6c), ductal epithelium almost filled the entire fat pad and terminal end buds were absent, suggesting that the gland was essentially quiescent. Administration of $\mathrm{E}$ caused extensive side branching and alveolar development (Fig. 6d, $20 \mu \mathrm{g}$ dose) reminiscent of early pregnancy. In addition, DNA content per mammary gland was increased about 40\% in E-treated 11-week-old mice, but not in 5-week-old animals (Table 1). This effect on alveolar morphogenesis was presumably mediated by combined systemic and local effects of $\mathrm{E}$, prolactin, and progesterone.

\section{KGF $m R N A$ expression in ovariectomized mice}

We compared KGF mRNA levels in ovariectomized and non-ovariectomized animals, to determine if endogenous
A
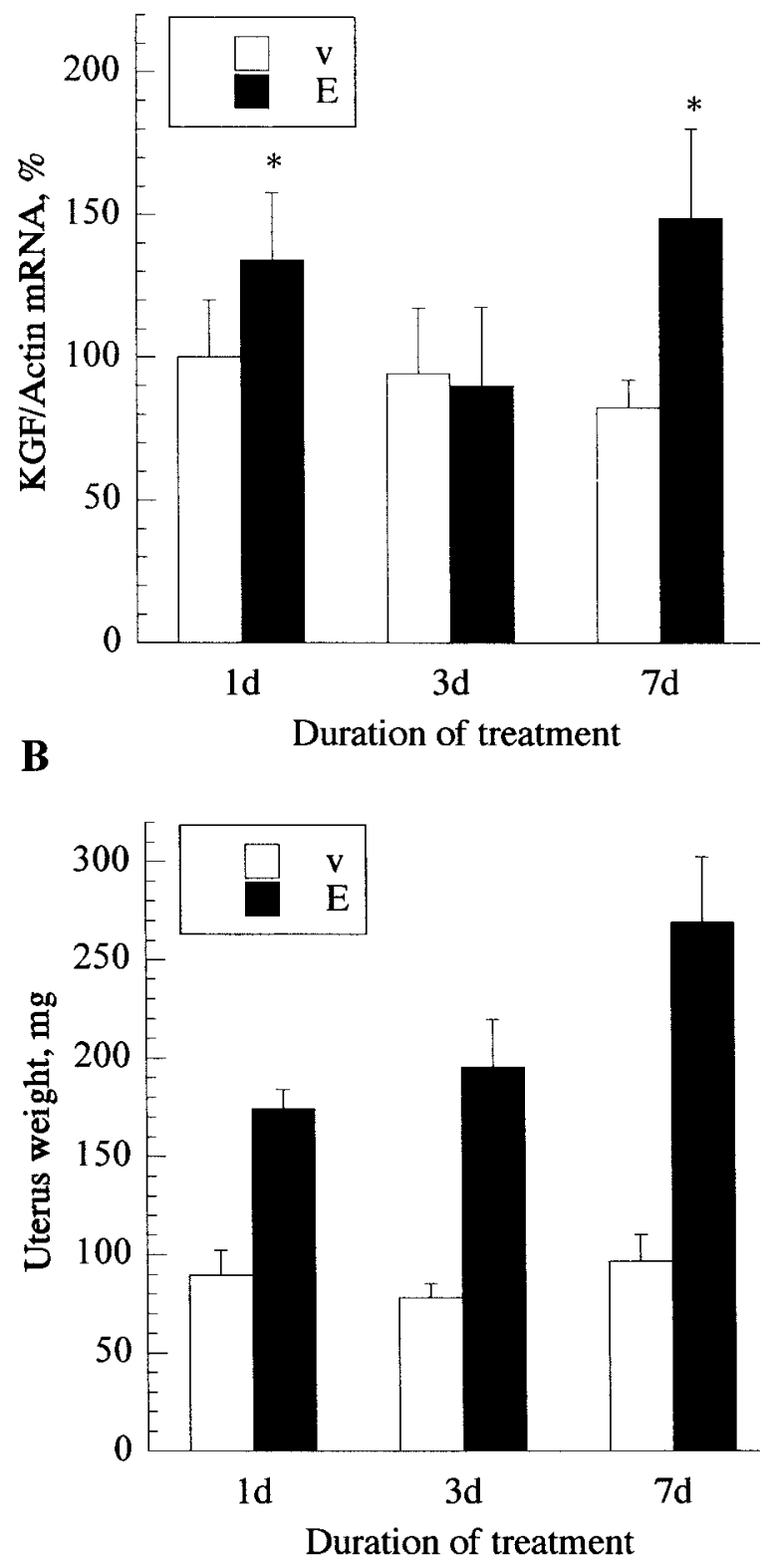

Figure 4 Time course of the $17 \beta$-estradiol (E) effect on expression of KGF mRNA in mammary glands of 11-week-old BALB/c mice. Mice were injected daily with vehicle control (v) or $20 \mu \mathrm{g} \mathrm{E}$. (A) After the indicated times (d, day), total RNA was extracted from mammary glands and KGF mRNA levels were measured as described in Fig. 1. The data are expressed as the percentage change compared with vehicle-treated animals at day 1 , which was arbitrarily set at $100 \%$. Bars represent means \pm S.D. of two experiments $(n=6) .{ }^{*} P<0 \cdot 05$ vs respective vehicle control group (unpaired Student's t-test). (B) Effect of $\mathrm{E}$ on uterine wet weight. Data represent means \pm S.D. $(n=6)$ from two experiments. 


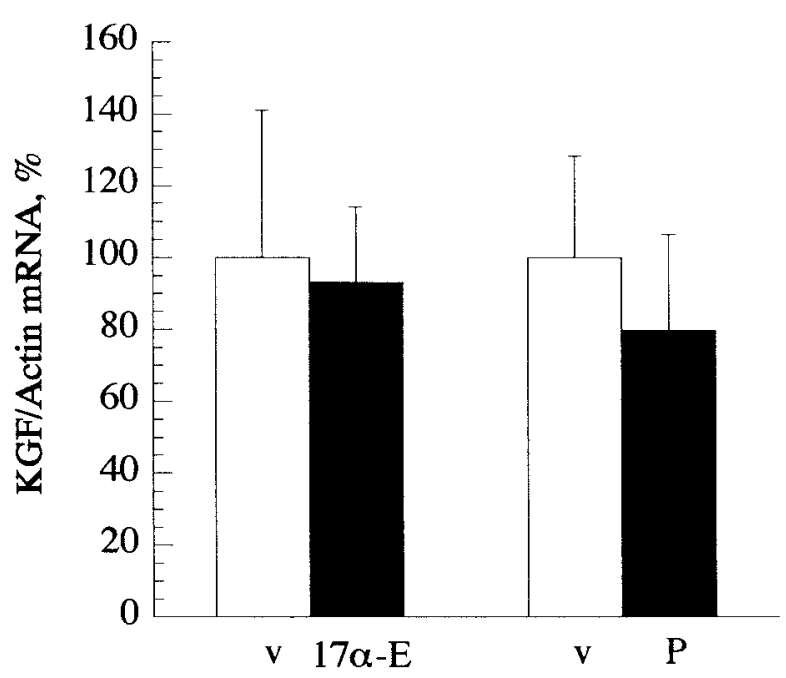

Figure 5 Effect of $17 \alpha$-estradiol $(17 \alpha-E)$ and progesterone (P) treatment on KGF mRNA levels in mammary glands of 5-week-old mice. Starting from 4 weeks of age mice were injected daily with $20 \mu \mathrm{g} 17 \alpha$-estradiol or $400 \mu \mathrm{g}$ P for 7 days and KGF mRNA levels in mammary glands were analyzed as described in Fig. 1. The data are expressed as the percentage change compared with vehicletreated animals $(v)$. Bars represent means \pm S.D. $(n=6$ for $17 \alpha$-estradiol, $n=9$ for progesterone).

ovarian steroids were affecting KGF expression in mature mice. Mice were ovariectomized at 10 weeks of age, and 2 weeks post ovariectomy RNA was extracted from the fourth inguinal mammary glands. No decrease in the basal level of KGF mRNA was observed in adult ovariectomized mice compared with non-ovariectomized mice. For data combined from 6 experiments (16 animals per group) values were $129 \pm 11 \%$ vs $100 \pm 6 \%$ respectively (means \pm s.E.M., $P<0 \cdot 05$ ), showing even a small increase in KGF mRNA.

\section{Effect of $E$ on KGF $m R N A$ levels in cleared \\ (parenchyma-free) compared with intact mammary glands}

It seemed possible that the diminished elevation of KGF mRNA by $E$ in 11-week-old mice compared with 5-week-old mice could simply reflect a decrease in the ratio of stromal to epithelial RNA in total RNA extracts occurring as a result of alveolar development. Similarly, the slight increase in KGF mRNA in ovariectomized mice (above) could be a consequence of ductal thinning and reduced branching observed in mammary glands of ovariectomized mice and, hence, an increase in the ratio of stromal to epithelial RNA. To examine this possibility, steady-state levels of KGF mRNA were compared in intact mammary glands and in cleared fat pads from 5- and 11-week-old mice.

In 5-week-old mice (Fig. 7A) there was no significant difference in basal KGF mRNA levels between cleared and intact fat pads. This finding is consistent with the low degree of epithelial development observed in whole mounts. The fold $\mathrm{E}$ stimulation of KGF mRNA was also essentially the same for both intact and cleared glands at this age.

In contrast to peripubertal mice, analysis of KGF expression in mammary glands from 11-week-old adult mice revealed that the basal level of KGF mRNA in cleared fat pads was higher than in intact glands (Fig. 7B) which exhibited full ductal development (Fig. 6c). E elevation of KGF mRNA levels in cleared fat pads was also significantly higher compared with intact glands. E increased KGF mRNA levels in cleared fat pads of 11-week-old mice to about the same extent as in cleared fat pads of 5-week-old mice (174\% vs 201\%), suggesting that the apparent decreased responsiveness to $\mathrm{E}$ in intact mammary glands of mature mice could be attributed to the stimulation of alveolar development and subsequent dilution of stromal RNA with epithelial RNA.

\section{Effect of $E$ on KGF protein levels}

In order to determine if the E-dependent increase in KGF mRNA was associated with elevated KGF protein levels, we developed a sensitive two-antibody sandwich ELISA as described in Materials and Methods. With the lowest detection limit of about $2 \mathrm{pg} \mathrm{KGF/ml} \mathrm{(Fig.} \mathrm{8A),} \mathrm{this} \mathrm{assay}$ shows readily detectable levels of KGF immunoreactive material in mouse mammary gland homogenates. The level of KGF protein was the same in control animals of 5 and 11 weeks of age (Fig. 8B), as observed for KGF mRNA. E treatment increased the level of KGF immunoreactive protein calculated per milligram of protein in mammary gland homogenates of peripubertal, but not mature mice. However, while $\mathrm{E}$ had no effect on total protein in mammary gland homogenates from peripubertal mice, the amount of protein recovered from mature mice after $\mathrm{E}$ treatment was about $50 \%$ higher than the control group (average for four experiments, $P<0 \cdot 05$ ). When adjusted to total protein per mammary gland, the total content of KGF per inguinal mammary gland was significantly higher after $\mathrm{E}$ treatment in both age groups, with an average increase of $67 \%$ for peripubertal and $51 \%$ for mature animals (Fig. 8B).

\section{Discussion}

Mammogenic hormones are the primary regulators of mammary gland development while growth factors can be considered to be downstream co-effectors of hormone action (Nandi et al. 1982, Imagawa et al. 1990). While the identification of the biological effects of growth factors and their synthesis in the mammary gland has progressed, we are limited in our understanding of the integration of hormone and growth factor regulation. These experiments 

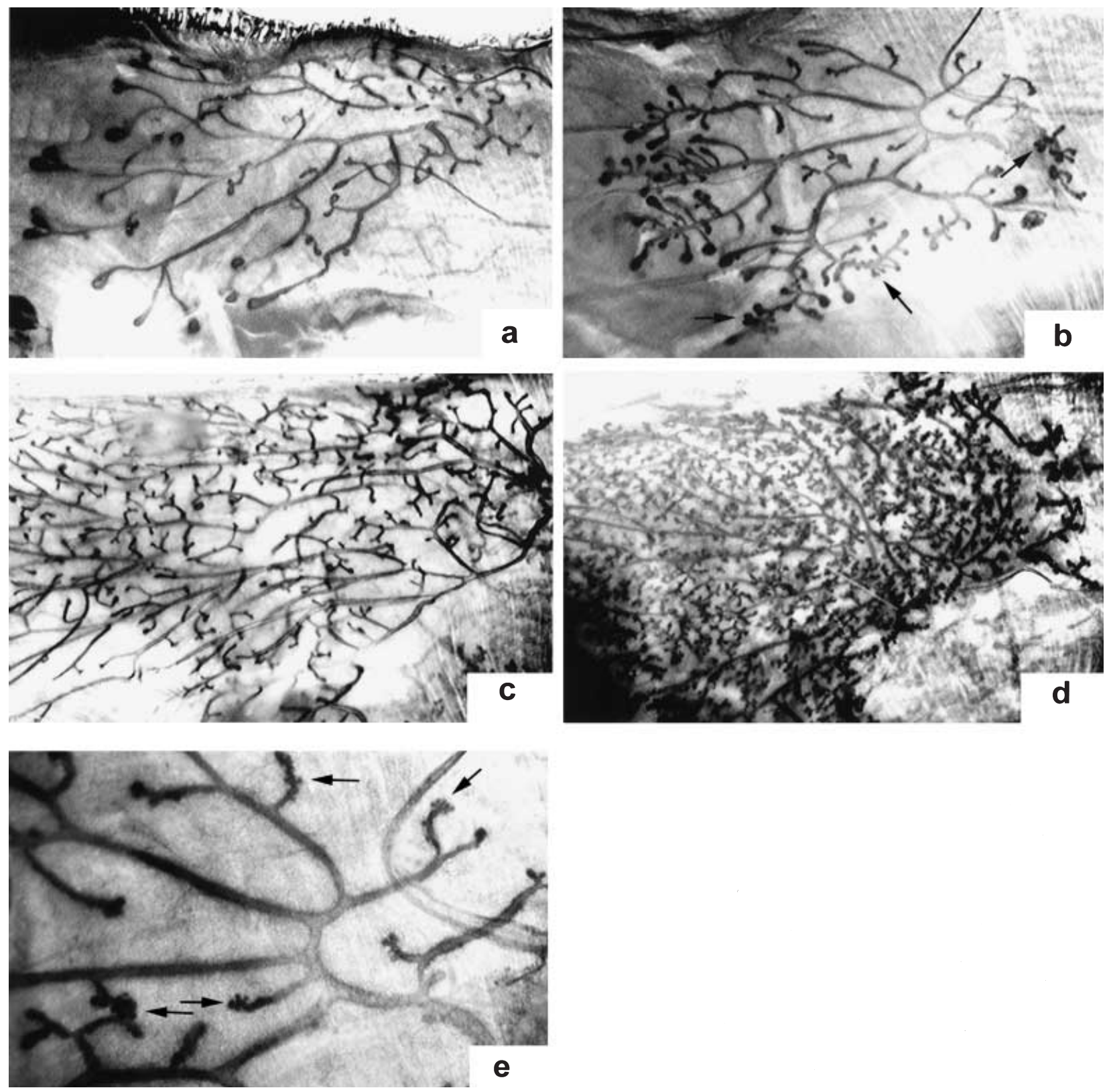

Figure 6 Mammary gland whole mounts from control and $17 \beta$-estradiol (E)-treated mice. Four- $(a, b$, e) or ten (c, d)-week-old female $\mathrm{BALB} / \mathrm{c}$ mice were injected daily with vehicle $(\mathrm{a}, \mathrm{c})$ or $20 \mu \mathrm{g} E(\mathrm{~b}, \mathrm{~d}, \mathrm{e})$ for 7 days. Note an increase in the number of terminal end buds, atypical non-dichotomous lateral branching and lobular budding (b, e; marked by arrows) in 5-week-old mice and extensive alveolar development in mammary gland of 11-week-old E-treated animals (d). Magnification $\times 10$ (a-d) or $\times 24$ (e).

addressed the hypothesis that mammogenic hormones orchestrate mammary gland development by integrating responses of the epithelial as well as stromal compartments of the mammary gland. The stromal compartment provokes interest as a hormonal target tissue since it is the site of growth factor synthesis and is hypothesized to be a site of hormone action relevant to mammary development (Cunha \& Hom 1996, Woodward et al. 1998).
We show that $\mathrm{E}$ treatment of both peripubertal and mature mice causes a dose- and time-dependent elevation in the steady-state level of stromally derived KGF mRNA in the mammary gland and an elevation in KGF protein. One point to remember is that the magnitude of the effect of $E(2 \cdot 5$-fold $)$ is probably not representative of the effect of $E$ on specific target cell populations. KGF mRNA and protein were assayed in RNA and protein preparations 
Table 1 The effect of $17 \beta$-estradiol treatment on mammary gland DNA content in 5- or 11-week-old BALB/c mice

DNA ( $\mu$ g per pair of fourth mammary glands)

\begin{tabular}{|c|c|}
\hline Vehicle & Estrogen \\
\hline $59 \cdot 1 \pm 1 \cdot 0(n=3)$ & $61 \cdot 3 \pm 1 \cdot 7(n=3)$ \\
\hline $121 \cdot 8 \pm 8 \cdot 2(n=9)$ & $172 \cdot 5 \pm 12 \cdot 6^{*}(n=9)$ \\
\hline
\end{tabular}

Four- or ten-week-old mice (number indicated in parentheses) were injected daily with vehicle or $20 \mu \mathrm{g} 17 \beta$-estradiol. After 7 days, RNA and DNA were extracted from the mammary glands with TRIzol reagent. DNA was isolated according to the manufacturer's recommendations and quantified by spectrophotometry.

${ }^{*} P<0 \cdot 01$; the estrogen-treated group has a higher DNA content than the control group.

that were representative of the whole mammary gland. Thus, the magnitude of the effect on the specific responsive cell population was diluted by contributions from non-responsive cells.

Unlike the primate uterus (Koji et al. 1994), progesterone treatment had no effect on KGF mRNA levels. This result suggests that this hormone is not involved in the regulation of KGF expression in the mammary gland. A direct effect of progesterone is not expected since progesterone receptors are not expressed in the stromal or adipose compartments of the mouse mammary gland (Shyamala et al. 1997). However, the lack of an effect in vivo shows that progesterone has no indirect effect on KGF mRNA levels mediated by a potential parenchymal-stromal interaction.

These new observations can be assembled with our previous results into a model describing the interactions between KGF and mammogenic hormones. Previously, we showed that progesterone, PRL, and PRL+ progesterone, when combined with KGF, synergistically stimulated the proliferation of mammary epithelial cells in vitro. Progesterone also enhanced KGFR mRNA stability, suggesting that part of its synergistic interaction with KGF might involve the modulation of the level of KGF receptors (Pedchenko \& Imagawa 1998). In contrast to progesterone and PRL, E did not affect either epithelial proliferation or KGF receptor expression in vitro. We can now hypothesize that progesterone and PRL might target principally the parenchymal compartment, and $\mathrm{E}$ the stromal compartment where KGF is synthesized. Thus, mammogenic hormones could act in concert to differentially modulate KGF bioactivity in the mammary gland by increasing the synthesis and secretion of KGF in stroma (E) and by potentiating its mitogenic effect on the epithelium (progesterone and PRL).

A previous report indicated that KGF mRNA was undetectable by Northern blot analysis in RNA from cleared fat pads of 5-week-old BALB/c mice (ColemanKrnacik \& Rosen 1994) leading to the proposal that its expression is dependent upon the presence of the
A

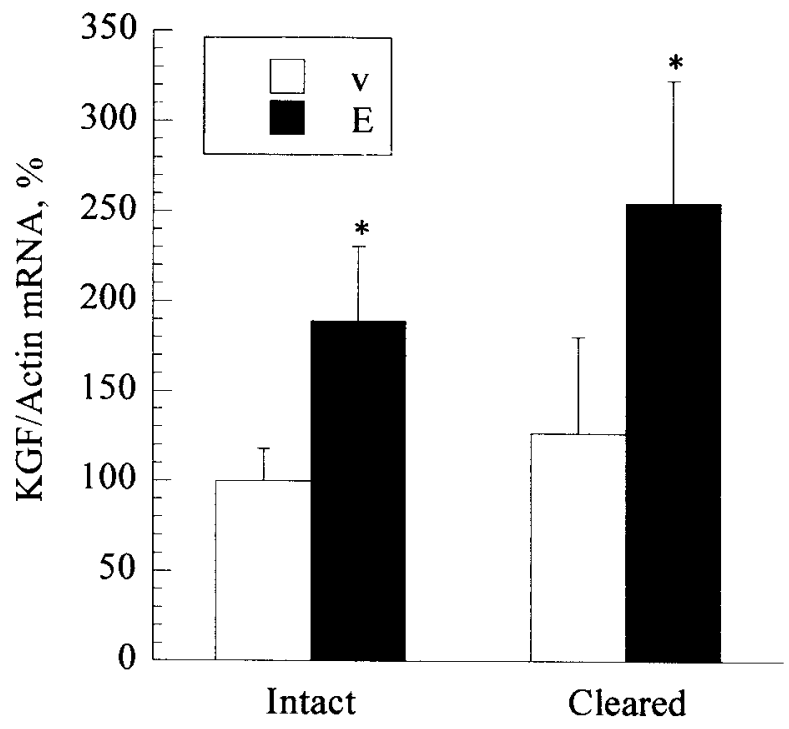

B

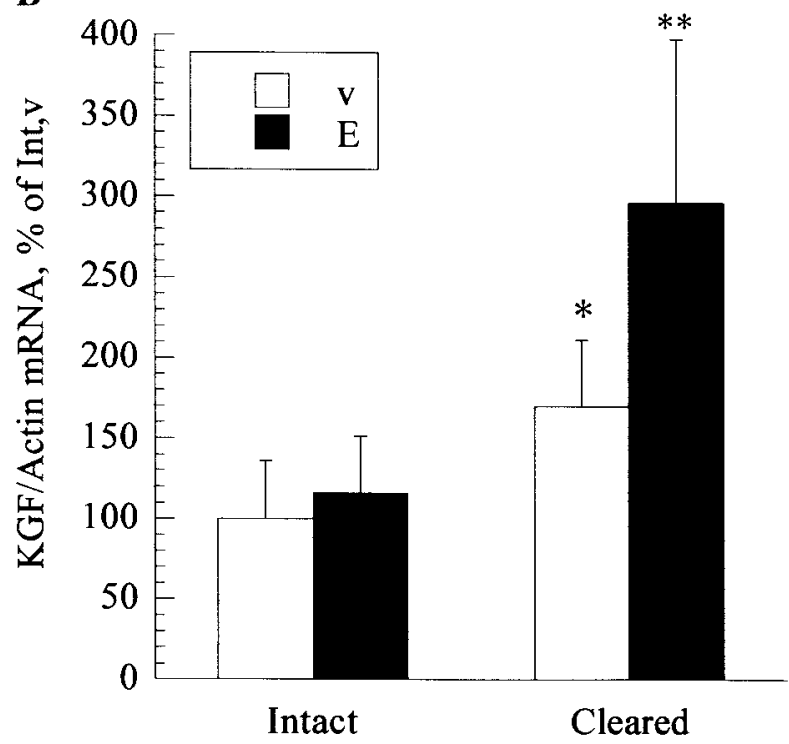

Figure 7 Comparative effect of $17 \beta$-estradiol (E) on KGF mRNA levels in intact mammary glands and cleared fat pads of 5-weekold (A) and 11-week-old (B) mice. Mammary glands were surgically cleared at 3 weeks of age. Starting from 4 (A) or 10 (B) weeks, mice were injected for 7 days with vehicle control (v) or $20 \mu \mathrm{g}$ E and KGF mRNA levels were measured as described in Fig. 1. The data are expressed as the percentage change compared with vehicle control intact animals. Bars represent means \pm S.D. $(n=6)$ from two experiments. ${ }^{*} P<0 \cdot 01$ vs respective vehicle control group in $A$ or vs vehicle control intact animals in B (unpaired Student's $t$-test).

${ }^{* *} P<0 \cdot 01$ vs vehicle control cleared animals.

parenchymal compartment. We find that KGF is expressed in cleared mammary fat pads and show that the level of expression is elevated by $\mathrm{E}$ similar to intact 
A

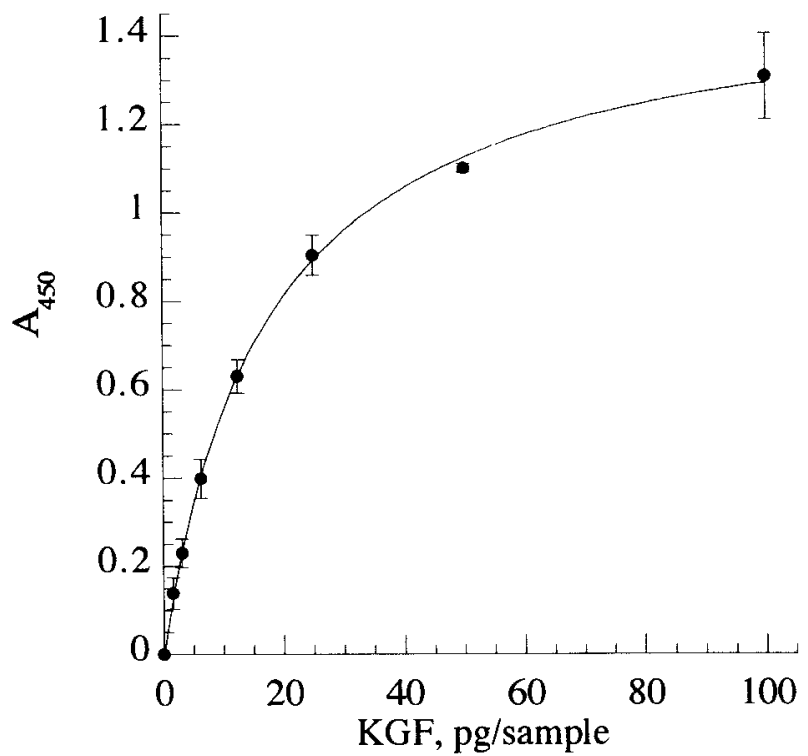

B

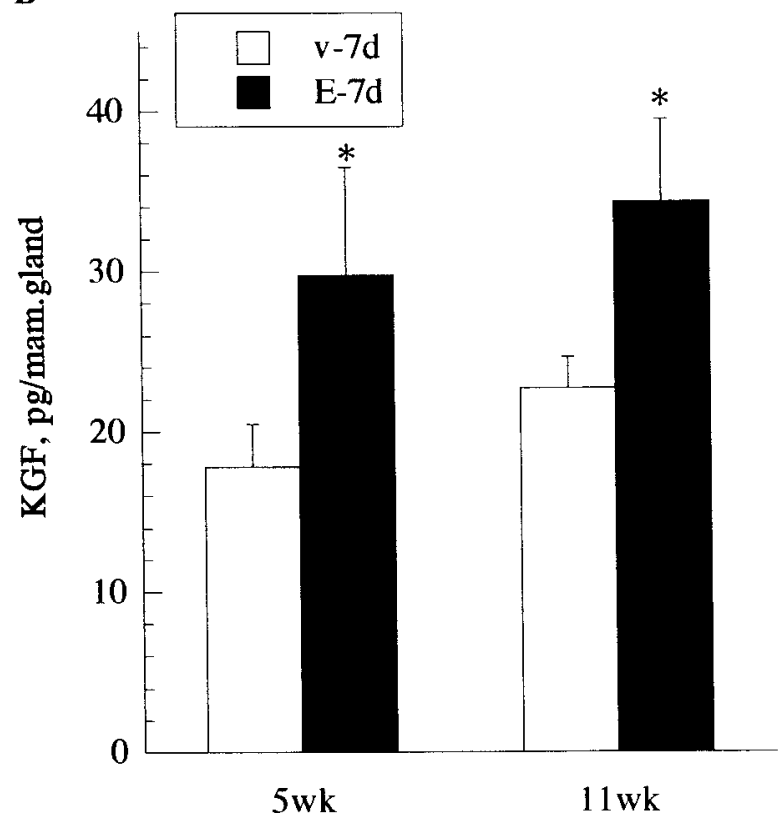

Figure 8 Measurement of KGF concentrations in mammary gland homogenates. (A) Standard curve obtained by hyperbolic regression of serial dilutions of recombinant human KGF assayed as described in Materials and Methods $\left(R^{2}=0 \cdot 999\right)$. A representative experiment is shown. Each data point was the mean of duplicate measurements. (B) Protein homogenates were prepared from mammary glands of 5- or 11-week-old mice treated for 7 days with vehicle $(\mathrm{v}-7 \mathrm{~d})$ or $20 \mu \mathrm{g} \mathrm{E}(\mathrm{E}-7 \mathrm{~d})$ and assayed for KGF by ELISA. Each bar represents the mean \pm S.E.M. of values from four ( 5 week) and three ( 11 week) independent experiments. ${ }^{*} P<0 \cdot 05$ vs respective vehicle control group (Student's t-test). mammary glands. Furthermore, E-regulated expression is not limited to periductal stroma which is absent in cleared fat pads. The reasons for this discrepancy may result from our use of a more sensitive ribonuclease protection assay. In these experiments, completeness of epithelial cell removal from mammary glands was confirmed by the absence of KGF receptor gene expression and by examination of whole mount preparations of cleared glands. In addition, KGF expression is confined to the extraparenchymal compartment since it is not expressed in isolated mammary epithelial cells (V K Pedchenko \& W Imagawa, unpublished observations). In vivo KGF expression in the absence of mammary epithelium indicates that neither its basal nor E-sensitive expression is dependent upon a reciprocal, hormone-dependent epithelial interaction. This does not eliminate the possibility, however, that the epithelium can modulate KGF expression via other mechanisms.

The regulation of KGF synthesis is most likely multifactorial exhibiting E-dependent and E-independent regulation as shown by the lack of an effect of ovariectomy on the basal level of KGF mRNA. In fact, it is possible that E-dependent regulation is itself multifactorial. The effect of $\mathrm{E}$ in vivo is significant at $24 \mathrm{~h}$ but clearly highest after 7 days of treatment. This prolonged time course could reflect the attainment of a sustained, optimal concentration or indicate that $\mathrm{E}$ acts via indirect as well as direct mechanisms. If PRL can directly affect KGF expression in the stroma then it can conceivably act as an estromedin since E stimulates PRL secretion. It is known that cytokines, including transforming growth factor $\alpha$ (Brauchle et al. 1994, Chedid et al. 1994, 1996), interleukins (Finch et al. 1995b), and cyclic AMP (Le Panse et al. 1996) can positively affect KGF synthesis, and the local elevation of any of these factors by E (or other factors) could positively affect KGF expression. Alternatively, negative regulators may exist. It has been shown that certain regions of the KGF promoter can inhibit as well as stimulate KGF expression (Finch et al. 1995b) and glucocorticoids (Chedid et al. 1996) can inhibit KGF expression. Thus, E could also elevate KGF expression by attenuating an inhibitory pathway.

What is the role of KGF in mammary gland development? E is necessary for ductal growth, predominantly during the pre- and peripubertal period during which $\mathrm{E}$ fails to induce progesterone receptors (Haslam 1988). KGF injection into rodents causes ductal proliferation, leading to ductal dilation in mice ( $\mathrm{Yi}$ et al. 1994) or extensive ductal thickening in rats (Ulich et al. 1994), but in neither rats nor mice can KGF alone stimulate alveolar development. Similar intraductal thickening is observed in transgenic mice in which KGF expression is driven by an MMTV promoter (Kitsberg \& Leder 1996). These findings strongly suggest that KGF is potentially a predominantly ductal mitogen. However, in pregnant rats where circulating ovarian steroids are elevated, KGF can 
apparently stimulate alveolar growth (Ulich et al. 1994) and the expression of a dominant negative KGF receptor construct inhibits alveolar rather than ductal development in mice (Jackson et al. 1997). These observations can be reconciled if KGF positively affects the second phase of ductal development occurring at the onset of pregnancy that accompanies alveolar growth and morphogenesis. This phase of ductal growth is most likely required for alveolar development. Conversely, KGF expression is highest in the prepubertal mammary gland (VK Pedchenko \& W Imagawa, unpublished observations) and it may play a role during this phase or during embryonic development, with expression in the postpubertal animal being redundant. KGF knock-out mice apparently breed and lactate normally (Guo et al. 1996) indicating that other ligands, potentially the newly characterized FGF-10 (Beer et al. 1997, Igarashi et al. 1998) or FGF-1 which bind with high affinity to the KGF receptor (FGFR-2IIIb), may substitute for KGF.

Clearly much needs to be learned about the hormonal regulation of multiple growth factors and receptors expressed in the mammary gland. The KGF paradigm is beginning to reveal how mammogenic hormones can collaborate to regulate the synthesis of a growth factor and its receptor, and modulate its biological activity via postreceptor mechanisms.

\section{Acknowledgements}

This work was supported by grant no. CA68414-01 from the NIH/NCI. The authors thank Drs Stuart Aaronson, Paul Finch, and Jeffrey Rubin for providing riboprobe vectors.

\section{References}

Aaronson S, Bottaro D, Miki T, Ron D, Finch P, Fleming P, Ahn J, Taylor W \& Rubin J 1991 Keratinocyte growth factor. A fibroblast growth factor family member with unusual target cell specificity. Annals of the New York Academy of Sciences 638 62-77.

Ankrapp D, Bennett J \& Haslam S 1998 Role of epidermal growth factor in the acquisition of ovarian steroid hormone responsiveness in the normal mouse mammary gland. Journal of Cell Physiology 174 251-260.

Basilico C \& Moscatelli D 1992 The FGF family of growth factors and oncogenes. Advances in Cancer Research 59 115-165.

Beer H-D, Florence C, Dammeier J, McGuire L, Werner S \& Duan D 1997 Mouse fibroblast growth factor 10: cDNA cloning, protein characterization, and regulation of mRNA expression. Oncogene 15 2211-2218.

Brauchle M, Angermeyer K, Hubner G \& Werner S 1994 Large induction of keratinocyte growth factor expression by serum growth factors and pro-inflammatory cytokines in cultured fibroblasts. Oncogene 9 3199-3204

Chedid M, Rubin J, Csaky K \& Aaronson S 1994 Regulation of keratinocyte growth factor gene expression by interleukin 1. Journal of Biological Chemistry 269 10753-10757.
Chedid M, Hoyle J, Csaky K \& Rubin J 1996 Glucocorticoids inhibit keratinocyte growth factor production in primary dermal fibroblasts. Endocrinology 137 2232-2237.

Coleman-Krnacik S \& Rosen J 1994 Differential temporal and spatial gene expression of fibroblast growth factor family members during mouse mammary gland development. Molecular Endocrinology 8 218-229.

Cooke P, Buchanan D, Lubahn D \& Cunha G 1998 Mechanism of estrogen action: lessons from the estrogen receptor- $\alpha$ knockout mouse. Biology of Reproduction 59 470-475.

Cunha G \& Hom Y 1996 Role of mesenchymal-epithelial interactions in mammary gland development. Journal of Mammary Gland Biology and Neoplasia 1 21-36.

Cunha G, Young P, Hom Y, Cooke P, Taylor J \& Lubahn D 1997 Elucidation of a role of stromal steroid hormone receptors in mammary gland growth and development by tissue recombination experiments. Journal of Mammary Gland Biology and Neoplasia 2 393-402.

Daniel CW, Silberstein GB \& Strickland P 1987 Direct action of $17 \beta$-estradiol on mouse mammary ducts analyzed by sustained release implants and steroid autoradiography. Cancer Research $\mathbf{4 7}$ 6052-6057.

DeOme KB, Faulkin LJ, Bern HA \& Blair PB 1959 Development of mammary tumors from hyperplastic alveolar nodules transplanted into gland-free mammary fat pads of female $\mathrm{C} 3 \mathrm{H}$ mice. Cancer Research 19 515-520.

Edery M, Imagawa W, Larson L \& Nandi S 1985 Regulation of estrogen and progesterone receptor levels in mouse mammary epithelial cells grown in serum-free collagen gel cultures. Endocrinology 116 105-112.

Finch P, Cunha G, Rubin J, Wong J \& Ron D 1995a Pattern of keratinocyte growth factor and keratinocyte growth factor receptor expression during mouse fetal development suggests a role in mediating morphogenetic mesenchymal-epithelial interactions. Developmental Dynamics 203 223-240.

Finch P, Lengel C \& Chedid M 1995b Cloning and characterization of the promoter region of the human keratinocyte growth factor gene. Journal of Biological Chemistry 270 11230-11237.

Guo L, Degenstein L \& Fuchs E 1996 Keratinocyte growth factor is required for hair development but not for wound healing. Genes and Development 10 165-175.

Haslam SZ 1986 Mammary fibroblast influence on normal mouse mammary epithelial cell responses to estrogen in vitro. Cancer Research 45 310-316.

Haslam SZ 1988 Acquisition of estrogen-dependent progesterone receptors by normal mouse mammary gland. Ontogeny of mammary progesterone receptors. Journal of Steroid Biochemistry 31 9-13.

Haslam SZ \& Shyamala G 1981 Relative distribution of estrogen and progesterone receptors among the epithelial, adipose, and connective tissue components of the normal mammary gland. Endocrinology 108 825-830.

Haslam S, Counterman L \& Nummy K 1993 Effects of epidermal growth factor, estrogen, and progestin on DNA synthesis in mammary cells in vivo are determined by the developmental state of the gland. Journal of Cell Physiology 155 72-78.

Igarashi M, Finch P \& Aaronson S 1998 Characterization of recombinant human fibroblast growth factor FGF-10 reveals functional similarities with keratinocyte growth factor FGF-7. Journal of Biological Chemistry 273 13230-13235.

Imagawa W, Tomooka Y, Hamamoto S \& Nandi S 1985 Stimulation of mammary epithelial cell growth in vitro: interaction of epidermal growth factor and mammogenic hormones. Endocrinology 116 $105-112$.

Imagawa W, Bandyopadhyay GK \& Nandi S 1990 Regulation of mammary epithelial cell growth in mice and rats. Endocrine Review 11 494-523. 
Imagawa W, Yang J, Guzman R \& Nandi S 1994a Control of mammary gland development. In The Physiology of Reproduction, edn 2, pp 1033-1063. Eds E Knobil \& J Neill. New York: Raven Press.

Imagawa W, Cunha G, Young P \& Nandi S $1994 b$ Keratinocyte growth factor and acidic fibroblast growth factor are mitogens for primary cultures of mammary epithelium. Biochemical and Biophysical Research Communications 204 1165-1169.

Jackson D, Bresnick J, Rosewell I, Crafton T, Poulsom R, Stamp G \& Dickson C 1997 Fibroblast growth factor receptor signalling has a role in lobuloalveolar development of the mammary gland. Journal of Cell Science 110 1261-1268.

Kitsberg D \& Leder P 1996 Keratinocyte growth factor induces mammary and prostatic hyperplasia and mammary adenocarcinoma in transgenic mice. Oncogene 13 2507-2515.

Koji T, Chedid M, Rubin J, Slayden OD, Csaky K, Aaronson S \& Brenner R 1994 Progesterone-dependent expression of keratinocyte growth factor mRNA in stromal cells of the primate endometrium: keratinocyte growth factor as a progestomedin. Journal of Cell Biology 125 393-401.

Le Panse R, Bouchard B, Lebreton C \& Coulomb B 1996 Modulation of keratinocyte growth factor KGF mRNA expression in human dermal fibroblasts grown in monolayer or within a collagen matrix. Experimental Dermatology 5 108-114.

Li Y \& Rinehart C 1998 Regulation of keratinocyte growth factor expression in human endometrium: implications for hormonal carcinogenesis. Molecular Carcinogenesis 23 217-225.

Matsui H, Taga M, Kurogi K \& Minaguchi H 1997 Gene expressions of keratinocyte growth factor and its receptor in the human endometrium/decidua and chorionic villi. Endocrine Journal $\mathbf{4 4}$ 867-887.

Nandi S, Imagawa W, Tomooka Y, Shiurba R \& Yang J 1982 Mammogenic hormones: possible roles in vivo. In Growth of Cells in Hormonally Defined Media, Book B, vol 9, pp 779-788. Eds GH Sato, AB Pardee \& DA Sirbasku. Cold Spring Harbor: Cold Spring Harbor Laboratory.

Nemeth J, Zelner D, Lang S \& Lee C 1998 Keratinocyte growth factor in the rat ventral prostate: androgen-independent expression. Journal of Endocrinology 156 115-125.

Parrott J \& Skinner M 1998 Developmental and hormonal regulation of keratinocyte growth factor expression and action in the ovarian follicle. Endocrinology 139 228-235.

Pedchenko V \& Imagawa W 1998 Mammogenic hormones differentially modulate keratinocyte growth factor KGF-induced proliferation and KGF receptor expression in cultured mouse mammary gland epithelium. Endocrinology 139 2519-2526.

Planz B, Wang Q, Kirley S, Lin C-W \& Mcdougal W 1998 Androgen responsiveness of stromal cells of the human prostate: regulation of cell proliferation and keratinocyte growth factor by androgen. Journal of Urology 160 1850-1855.

Rubin J, Bottaro D, Chedid M, Miki T, Ron D, Cunha G \& Finch P 1995 Keratinocyte growth factor as a cytokine that mediates mesenchymal-epithelial interaction. EXS 74 191-214.

Shyamala G, Barcellos-Hoff M, Toft D \& Yang X 1997 In situ localization of progesterone receptors in normal mouse mammary glands: absence of receptors in connective and adipose stroma and heterogeneous distribution in the epithelium. Journal of Steroid Biochemisty and Molecular Biology 63 251-259.

Studnicka G 1987 Hyperbolic regression analysis for kinetics, electrophoresis, ELISA, RIA, Bradford, Lowry, and other applications. Computer Applications in Biosciences 3 9-16.

Sugimura Y, Foster B, Hom Y, Rubin J, Finch P, Aaronson S, Hayashi N, Kawamura J \& Cunha G 1996 Keratinocyte growth factor, KGF, can replace testosterone in the ductal branching morphogenesis of the rat ventral prostate. International Journal of Developmental Biology 40 941-951.

Thomson A, Foster B \& Cunha G 1997 Analysis of growth factor and receptor mRNA levels during development of the rat seminal vesicle and prostate. Development 124 2431-2439.

Topper YJ \& Freeman CS 1980 Multiple hormone interactions in the developmental biology of the mammary gland. Physiology Review $\mathbf{6 0}$ 1049-1106.

Ulich T, Yi E, Cardiff R, Yin S, Bikhazi N, Biltz R, Morris C \& Pierce G 1994 Keratinocyte growth factor is a growth factor for mammary epithelium in vivo. American Journal of Pathology 144 862-868.

Woodward T, Xie J \& Haslam S 1998 The role of mammary stroma in modulating the proliferative responce to ovarian hormones in the normal mammary gland. Journal of Mammary Gland Biology and Neoplasia 3 117-131.

Xie J \& Haslam S 1997 Extracellular matrix regulates ovarian hormone-dependent proliferation of mouse mammary epithelial cells. Endocrinology 138 2466-2473.

Yi E, Bedoya A, Lee H, Kim S, Housley R, Aukerman S, Tarpley J, Starnes C, Yin S, Pierce G et al. 1994 Keratinocyte growth factor causes cystic dilation of the mammary glands of mice. American Journal of Pathology 145 1015-1022.

Zeps N, Bentel J, Papadimitriou J, D’Antuono M \& Dawkins H 1998 Estrogen receptor-negative epithelial cells in mouse mammary gland development and growth. Differentiation 62 221-226.

Received 20 July 1999

Accepted 25 November 1999 